\title{
THE 2018 AANS PRESIDENTIAL ADDRESS The privilege of service
}

\author{
Alex B. Valadka, MD, ${ }^{1}$ Jaclyn S. Valadka, MA, ${ }^{2}$ Patrick R. Valadka, MBA, ${ }^{3}$ and \\ Patricia C. Valadka, BSN, RN ${ }^{4}$
}

1Department of Neurosurgery, Virginia Commonwealth University, Richmond, Virginia; ${ }^{2}$ Department of Psychological Sciences, University of Missouri, Columbia, Missouri; ${ }^{3}$ Austin, Texas; and ${ }^{4}$ Richmond, Virginia

\begin{abstract}
The theme of the 2018 American Association of Neurological Surgeons Annual Meeting was "The Privilege of Service." In the current climate of rapid change in healthcare delivery and increasing pressure on physicians, this theme was chosen to remind us of our true priorities and of the amazing opportunities that we have as neurosurgeons. In parallel to the classic triple-threat practitioner who excels in teaching, research, and clinical care, future neurosurgeons will need to acquire mastery in three areas of service, which have been summarized as the three A's: administration, advocacy, and altruism. The blessings that we enjoy afford us a platform from which we can take advantage of the many opportunities to experience the privilege of serving others.
\end{abstract}

https://thejns.org/doi/abs/10.3171/2018.7.JNS182047

KEYWORDS neurosurgery; presidential address; AANS

$\mathrm{T}$ HE president of the American Association of Neurological Surgeons (AANS) carries the responsibility of living up to the lofty standards set by the preceding presidents (http://www.aans.org/en/About-Us/ Governance/AANS-Presidents). The earliest presidents included the pioneers of our specialty. The more recent ones are the current superstars of our field. They all deserve thanks not only for what they have done for the AANS, but also for what they continue to do, both publicly and behind the scenes. Being part of this group and serving as the president of the premier society of the premier specialty in all of medicine has been the greatest honor of my career.

Every AANS president becomes keenly aware of the many people who provide essential help and guidance. They include the outstanding AANS staff in Rolling Meadows, Illinois, led by Kathleen Craig and, before her, by Tom Marshall. Our equally outstanding Washington Committee, led by Katie Orrico, is second to none. The selflessness and commitment of the AANS Executive Committee, Board of Directors, and countless other physician volunteers have been a constant source of inspiration.

Thanks are also due to the great many teachers, colleagues, and especially patients who provided encouragement and guidance and kept me pointed in the right direction.
The lion's share of thanks goes to my family. All of us in this specialty work long days in our service to others. It is important to remember that we do not do so in a vacuum. When we became neurosurgeons, we also committed our families to a life of service. Although they did not have a vote, our loved ones are expected to bear the consequences of our decision, including spending many hours without us. I cannot give enough thanks to my children and especially to my wife for the sacrifices they had to make so that I could give a career in neurosurgery the time and attention it demands.

\section{Gratitude}

We are blessed to be able to practice neurosurgery. But it is often far too easy for us to get worn down by the hassles of daily life: preauthorizations, peer-to-peer conferences with insurance companies, operating rooms running behind schedule, senseless rules about what we can and cannot wear into surgery, relentlessly multiplying regulations that threaten to overwhelm neurosurgical practice and training, the scarcity of research and education dollars, and on and on. Our colleagues who have served in Iraq and Afghanistan tell us that one of the few good things about that experience was the total focus on taking 
care of the patient. No preauthorizations, no turf issueseveryone just does what needs to be done. If the neurosurgeon has to put in a central line or a chest tube, he or she just takes care of it and moves on. How very different from the civilian world.

Despite these hassles, or perhaps because of them, it is important that we come up for air every once in a while and appreciate the wonder of what we do. We relieve pain and restore function. We give our patients the opportunity to reclaim their lives.

Several years ago, as an administrative colleague and I were engaged in frustrating and fruitless struggles to bring much-needed reform to our hospital system, I was on call on what became a very busy evening. The next morning, I sent her a text message that said, "I saved two lives last night. Maybe this job isn't so bad after all!" Every neurosurgeon can tell similar stories; very few other people can. We need to remember to take an occasional pause to marvel at our patients, at what we are able to offer them, and at the beauty and magic of the nervous system.

There is a unique bond among those of us who do this extraordinary work. Leaders from other medical specialties tell us that neurosurgeons are different. We are natural leaders. We work very hard, and we get things done. The very nature of what we do leads society to view us differently than it does other physicians. The fellowship we enjoy as we work in this most amazing field is priceless. We truly are a band of brothers and sisters. Without a doubt, one of the best things about this career is the friends we make along the way-colleagues as well as patients.

\section{New Triple Threat}

We are all familiar with the so-called "triple-threat" academician: someone who excels as a clinician, an educator, and a researcher. Of course, this is largely an artificial construct. Explosive growth in knowledge makes it challenging to remain current in any one of those three activities, much less two of them. But this is still a useful model for thinking about the expectations placed on those in academic practice.

The metrics used to judge success in academics may include numbers of such items as grants, publications, presentations, and patents, or the speed with which promotion and tenure are earned, or other similar measures. In private or hybrid or employed practice, as well as in academics, the most common measures of success relate to clinical productivity and generation of revenue. Unfortunately, these pressures to focus on individual numbers can lead to self-centered behavior instead of true service to our patients, our trainees, our colleagues, and our community. The result is a diminishing of the good that we can do as neurosurgeons.

Instead, teamwork and service define the new skills that we will need and roles that we will play if we are to survive and thrive in the future not just in our individual practices, but as a specialty. Those who master these new skills make up a new triple threat that runs in parallel to the classic one. These three new areas that we need to master are the three A's: administration, advocacy, and altruism.

\section{Administration}

The first of these new areas is administration. Many neurosurgeons run as far as they can from this work and even look down upon those who perform it. It is true that the pace and rhythm of administrative work are very different from those of a neurosurgeon's daily routine. When a neurosurgeon is driving home after a good day, he or she is happy because they have helped a few patients in the operating room (OR), the intensive care unit (ICU), the clinic, or the emergency department (ED). It is hard to get that same kind of immediate gratification after a day spent in meetings.

But this raises an important question: what don't we like about being neurosurgeons? We do not complain about taking care of patients. That is what we signed up for. Instead, the complaints are about how the turnover time in the OR is too long, how the hospital is run inefficiently, how third-party payers are impossible to work with, and so on.

How many of us think that the best way to solve these problems is to complain to each other in the hospital corridors or in the OR? Instead, the best way to change things is to become a decider. Someone will be making these decisions. Who is better qualified than a neurosurgeon? Every day, we travel through all the clinical areas of the hospital: OR, ICU, procedural suites, inpatient wards, ED. We interact with radiologists, pathologists, anesthesiologists, pediatricians, neurologists, internal medicine physicians, family practitioners, advanced practice providers, nurses, therapists, and many others. We see outpatients in clinic. We are part of cancer networks and regional systems for stroke, trauma, and other emergency care. The broad spectrum of what we do makes us perfectly positioned to direct large organizations. Certainly, anyone who can make it through medical school and neurosurgery residency has the grit to learn to be an effective administrator.

Although many administrators are strong leaders, the two roles are not synonymous. The word "leadership" is one of the most overused and misused terms in our society. Anyone with any sort of administrative role is automatically described as a "leader." Sadly, few people referred to as leaders actually live up to the name. True leadership is more about selflessly serving those we lead than about holding any specific position. Every neurosurgeon knows individuals in administrative roles who are more interested in titles and in protecting their turf than in actually making things better. It soon becomes obvious that these individuals are in way over their heads.

Fortunately, the most important activity in any organization takes place outside the boxes and lines on the formal organizational chart (Fig. 1). This has at least two implications. One is that it is possible to use these unofficial channels to neutralize or bypass ineffective or obstructive administrators. Another is that people without any formal administrative titles may still be powerful leaders and influencers within the organization. Thus, although holding a position as a committee member or chair or as a medical director creates a recognized platform from which to lead, many influencers do not have such formal roles. Rosamund Stone Zander writes, "When leadership is defined not as a place you hold, but as a way of being, you discover 


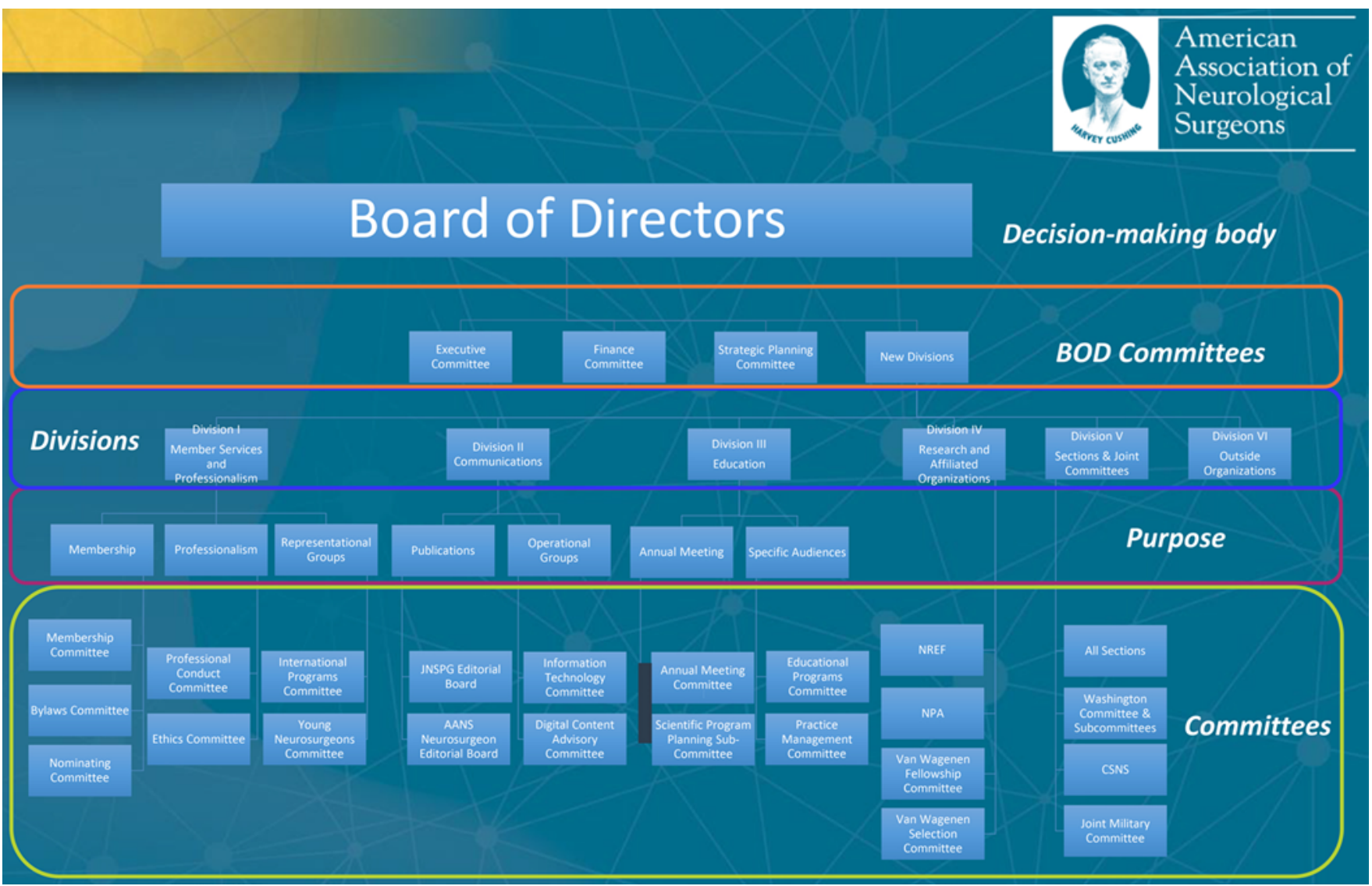

FIG. 1. Organizational chart of the AANS. CSNS = Council of State Neurosurgical Societies; NPA = NeuroPoint Alliance; NREF = Neurosurgery Research \& Education Foundation. Figure is available in color online only.

that you can lead from wherever you are." 11 It is easy to identify these unofficial leaders. They are the people to whom others go when they want to get things done.

For both official and unofficial leaders, the most important decision is to step up and take action. We have all heard versions of the idea that $80 \%$ of success is just showing up. ${ }^{2}$ And if we do not show up, someone else will be sitting in our seat and making decisions for us.

Successful leadership also requires both self-awareness and situational awareness. We need to be conscious of the impact of our words, our actions, and even our body language. Like it or not, we are already leaders in our medical communities because of the very fact that we are neurosurgeons. We stand out. Other people pay especially close attention to us. What kind of leader are you? Do people want to be in your room when you are operating? Do they want to work with you in clinic? When others see you coming down the hall, do they want to stop and say hello, or do they try to avoid you? What do you bring to your relationships? Do you enhance or diminish others?

\section{Advocacy}

Administration and leadership make up the first of the new-triple threat roles that we have to master in the healthcare world of tomorrow. A second is advocacy.

When we hear the word advocacy, most of us think about political and regulatory systems and about lobbying efforts aimed at politicians and regulatory agencies.
These activities are essential, and organized neurosurgery in this country is very well positioned in these areas. But our advocacy efforts need to be much broader. We need to be advocates and ambassadors for our specialty and for the medical profession as a whole. We need to educate the community about what we do. Why? Because the public is paying for it.

Economic activity is often quantified as gross domestic product, or GDP, which is the total value of goods produced and services provided in a specific region during a specific period of time. It is often used to describe a country's annual economic activity. Spending on healthcare currently makes up more than one-sixth of the GDP of the United States. That figure will exceed one-fifth, or $20 \%$, of the GDP within the next decade. ${ }^{3}$ More than 20 cents of every dollar-a penny out of every nickel-will soon be going to healthcare.

Annual healthcare costs approximate $\$ 3.5$ trillion in this country. ${ }^{3}$ Much of this is paid by governments at all levels, including 1) direct payments for such entities as the Veterans Affairs healthcare system, Medicare, Medicaid, the National Institutes of Health, and public health departments; 2) government payments for health insurance for public employees; and 3) tax subsidies for healthcare by governments at all levels, from local to federal. ${ }^{6}$ These taxfunded health expenditures accounted for over $64 \%$ of US health spending in 2013. That proportion will exceed twothirds within the next 10 years. ${ }^{6}$ Most of the remaining 
third is paid by individuals through insurance premiums or direct out-of-pocket expenditures. That means that we, our neighbors, our patients, and our employers are footing this country's medical care bill through taxes and insurance premiums. When people have that much skin in the game, sooner or later they want to know where their money is going and what they are getting for their healthcare dollar. We need to tell them.

We can also advocate for our practices, our hospitals, and for the other institutions with whom we work. The complexity of what we do as neurosurgeons requires us to partner with highly resourced healthcare systems and hospitals that have sophisticated ORs and other equipment. These healthcare systems are important parts of their communities. They provide jobs, generate significant economic activity, serve as safety nets, train tomorrow's healthcare providers, offer venues for clinical research, and play growing roles in the health of their communities. They also receive tax benefits and other government concessions. Legislators and taxpayers need to understand not only what they are subsidizing, but also what benefits they are receiving in return.

It goes without saying that the most important group for which we can advocate is our patients. We need to help them realize that they have much more control over their health than we do. Teaching the basics of a healthy lifestyle is far better than reinforcing the false hope that physicians can miraculously undo the effects of years of harmful personal habits. We need to encourage people to take more personal responsibility for their own health. Because the words we use influence the way we think, we can even argue that we should stop the current practice of referring to medical professionals as health care providers. We do not provide health. We simply provide medical care when people's management of their own health goes off track and needs our assistance to get back on course. This is an essential but under-recognized way for us to serve both our patients and our communities.

\section{Altruism}

The final part of the new triple threat-the third A-is altruism. This can be thought of as volunteerism, or community service, or giving back. Why should we do this? The answer is simple: it is the right thing to do.

Our ancestors across the globe recognized this thousands of years ago. Every major religion stresses that we must take care of each other: not just family and friends, but those who are different from us-strangers and even enemies. In the ancient religions of Hinduism and Buddhism, we find the idea of karma, or the concept that the sum of a person's actions decides his or her fate. Most of us have heard the 2000-year-old story of the Good Samaritan in the Gospel of Luke (Luke 10:30-37). ${ }^{8}$ A Jewish man who was beaten and robbed is ignored by leaders of his faith community. He is eventually cared for by a Samaritan, even though Jews and Samaritans at that time were bitter enemies. The Jewish community of that era must have been scandalized by that story. Imagine retelling that parable in a modern context. What groups would we use instead of Samaritans and Jews? If we had an opportunity to act like a modern-day Samaritan, would we behave with the same degree of compassion?
Religion aside, most of us believe in universal principles of justice and fairness. "What goes around comes around" is a modern-day expression of the idea of karma. We like to think that those who cheat, lie, steal, or behave badly will sooner or later get caught and be made to atone for their misdeeds.

Ironically, there are also selfish reasons to act altruistically: it makes us feel good, and it is good for us. In his classic book The 7 Habits of Highly Effective People, Stephen Covey calls the seventh habit "sharpening the saw," which is his way of stressing the importance of a lifestyle that allows for physical, intellectual, and emotional renewal. ${ }^{4} \mathrm{He}$ emphasizes service to society as a gateway to maintaining spiritual renewal. Many other authors have described service in a similar way.

In addition, heeding the call of service may help to combat burnout, which has emerged as a huge problem for those in the medical field, as well as for the medical care system as a whole. Recommendations about preventing burnout emphasize the importance of volunteering, of serving, of looking outward.

Years ago, while I was a student at the University of Dallas, Dr. Gene Curtsinger led our literature class into a discussion of those types of human experience that take us out of ourselves and make us lose all sense of time. He listed four. One is the artistic experience. We can get so swept up in a song, a poem, a novel, a painting, a sculpture, a movie, a play, a dance performance, or other artistic expression that we lose ourselves. Another example is profound religious experience. A third is sex. The fourth is sports and athletic endeavor. One of my classmates asked him about the heroic act, such as running in front of an oncoming car to pull a small child to safety. He agreed that that was another good example.

Years later, I identified another activity that belongs on this list. Every surgeon can relate to this: the experience of being in the operating room when everything is in perfect sync. We can get so focused on what we are doing that we lose ourselves in the surgery.

Psychologist Mihaly Csikszentmihalyi described this phenomenon as "flow," or a highly focused mental state that grows out of one's own intrinsic motivation. ${ }^{5}$ A popular description of this is being "in the zone."

But these experiences that take us outside of ourselves share one problem. They are episodic, with a specific beginning and end. Is it possible to identify a different type of such experience? One that is always there and always on? At the risk of stretching this concept too far, I suggest that the answer is yes. The answer is found in dedication to service. Instead of Gene Curtsinger's activities that give us only a temporary immersion in something beyond ourselves, we can create a less intense but continuously operating way of getting outside ourselves by developing the mindset and the habit of looking for opportunities to serve others.

Just like our definition of advocacy, we use the term altruism in the broadest possible sense. Altruism can take many forms, big or little, continuous or episodic. Common examples include volunteering at a homeless shelter or crisis center, or at one of the many community or faith-based groups that serve others, or assisting in your child's school 
or other activities. Or dedicating time, effort, and talent to a children's hospital, a cancer center, or a hospice. Altruism includes our roles as advocates for our specialty, our profession, or the organizations for which and in which we work. Closer to our specialty, we can dedicate our time to service to professional organizations, to academic journals that ask for reviews of submitted manuscripts, to research funding agencies that require grant applications to be critiqued, or to students, residents, or colleagues who need mentoring, coaching, advice, or just someone to talk to.

A unique and incredibly important form of altruism presents itself to us as neurosurgeons when we give a patient a diagnosis of glioblastoma, or tell a family that their loved one has just suffered a devastating stroke or traumatic brain injury, or similar types of encounters. Our patients' and their family members' lives are turned upside down by such diagnoses. Our minimum responsibility is to describe for them the diagnosis, prognosis, treatment plan, and what to expect in the coming days and weeks. But at such emotional moments, it would be very charitable to take some extra time with these patients and families and answer questions, listen, or simply sit with them in silence. They will remember that conversation for the rest of their lives. It is our choice as to whether those memories will be uniformly negative, or whether their recollection of that conversation with the neurosurgeon stands out as a bright spot in an otherwise grim story.

Excellent examples of service and altruism can be found among those who serve in the military. They serve our country, and in doing so, they serve us. They willingly put up with the inconveniences of military service, including time away from loved ones and income that is lower than what they would receive in the private sector, because altruism is so important to them.

Some of our colleagues devote significant amounts of time to international service. Merwyn Bagan enjoyed a highly successful neurosurgical career that included a year as president of the AANS. He and his wife are also the single largest contributors to the Neurosurgical Research \& Education Foundation. Instead of retiring to a life of comfort, they moved to Nepal to provide neurosurgical services and establish a neurosurgical training program there. Mike Haglund combines a busy practice and a successful academic career at a top-flight research institution with frequent visits to Uganda, where he has raised the level of care and created a structure for neurosurgical training.

Early in my term as president of the AANS, I was privileged to attend the meeting of the New England Neurosurgical Society. I particularly remember a conversation with Andy Wakefield of Connecticut, who serves on the Board of Directors of the AANS. We talked about neurosurgeons volunteering in developing countries for brief visits to help underprivileged people who are often in desperate need of neurosurgical care. Andy is convinced that this kind of volunteerism is much more widespread than most people think. In a very casual way, almost as an afterthought, he said, "It's the right thing to do. We make a difference."

One of the most inspiring people I met during my service as AANS President is Kee Park, a Paul Farmer Global Surgery Scholar at Harvard. In another seemingly casual conversation that ended up being an eye-opener for me, he mentioned that he was wondering what he needed to do to maintain his American Board of Neurological Surgery certification since he was planning on spending his career practicing not in the United States, but only in developing countries. He also works with the World Health Organization to develop global health strategies for surgical care.

Most opportunities to serve do not require the same degree of meticulous planning that is needed to organize volunteer efforts in developing countries. Some of the most influential leaders who helped New Orleans get through the devastation of Hurricane Katrina had only a few hours to decide whether and how to help. They had the means to leave. Instead, they chose to stay and help, and their efforts made a big difference.

Last December, Nate Selden, the Chair of the Department of Neurological Surgery at Oregon Health \& Science University in Portland, happened to be driving in Seattle when he came across the scene of a devastating train accident. Several people died, and scores were injured. Nate could have looked the other way and could have claimed (as we all can) that he had too many things to do and could not take the time to stop. Instead, he and his son pulled over and worked for hours with first responders to treat the injured.

The more we look for opportunities to serve, the more we find. The next time we find ourselves on an airplane, what will we do if a flight attendant suddenly asks if there is a doctor on board? Will we ring the call button, or will we try to sink lower into our seats and keep looking down?

\section{Priorities}

What is the cost of service? Many employers or practice groups try to keep neurosurgeons in the OR as much as possible because they want to maximize revenues. Time spent on education, research, and administration, and even in clinic and on rounds, is minimized. But accepting roles as mere revenue-generating technicians will only come back to haunt us and our specialty in the long term. What will we do when the reimbursement structure for medical care changes to a fee-for-value system? The big cases that currently generate large amounts of income for surgeons and hospitals will suddenly become major expenses that consume most of the fixed payment for a particular patient's episode of care. We need to identify new ways to generate the funding that will support our practices, our institutions, our educational programs, and our new research efforts.

To put money into perspective, it is illustrative to consider how extreme poverty is conceptualized by many international aid and development groups. Although this is a highly complex and multifaceted problem that encompasses many dimensions of human suffering, one commonly used definition is based on daily income. The daily income threshold below which extreme poverty was defined in 1990 was 1 United States dollar (US\$), ${ }^{10}$ which gave rise to the phrase "living on a dollar a day." In 1985 more than one billion people, or almost one-third of the total population of the developing world, fell below that threshold ${ }^{10}$ which equated to more than $20 \%$ of the esti- 
mated world population of 4.85 billion at that time. The World Bank has updated that definition several times to adjust for inflation and for variation in the costs of goods and services in different countries. The most recent definition is a daily income below US\$1.90, and the most recent data indicate that, in the year 2013, the percentage of the world's population that lives in extreme poverty has continued to decrease, down to $10.7 \%$. ${ }^{9}$

At risk of getting lost in the economic and mathematical calculations is one sobering fact: hundreds of millions of people live on less money each day than we spend on a single cup of coffee or bottle of water.

How much money does it take to make us happy? In other words, if people start at very low incomes, and then their incomes gradually increase, at what level does their happiness stop increasing along with their incomes? In 2010, Princeton researchers Daniel Kahneman and Angus Deaton, who have each won the Nobel Prize for Economics, put that number at about US\$75,000 a year. As they stated in the abstract of their paper, "We conclude that high income buys life satisfaction but not happiness...."7 Once we can afford basic needs like food, clothing, and shelter, making more money does not affect our happiness nearly as much as when we are below that line. Perhaps those with high incomes who are unhappy and who think that even more money will make them happy would do better to reexamine their priorities.

In this discussion about money, it must be emphasized that neurosurgeons absolutely should be compensated for the years of grueling effort we spend honing our craft and for the commitment we need to deal with the complex conditions we treat. When our friends from high school, college, and even medical school are firmly established in their jobs and careers, we are still in training. We must master a complex body of knowledge that will continuously evolve during our careers. Once we enter practice, the workdays are long. Work-hour limits that restrict residency training do not apply to attending neurosurgeons. Most importantly, the high stakes of what we do and the emotional burden of treating patients with devastating diseases take their toll on many of our colleagues.

Money can be a remarkable tool for facilitating service to our fellow men and women. Perhaps the best example of this is Bill Gates. He had a brilliant idea, worked very hard, and became one of the richest people in the world. He then used his money to create a foundation that has improved the lives of millions of the world's poorest people. Many, many entrepreneurs and businessmen and businesswomen do the same things on a not-quite-so-grand scale. We as neurosurgeons are in a position to serve others not only through our craft, but also through our generosity. The often-heard comment that "money is the root of all evil" is actually an incomplete recitation of a New Testament verse. The complete quote states, "The love of money is the root of all evils and there are some who, pursuing it, have wandered away from the faith and so given their souls any number of fatal wounds" (1 Tim. 6:10). ${ }^{8}$

This is how some of our colleagues get into trouble. They lose sight of what is really important. If professional athletes start to worry more about salaries and endorsement deals than about their sport, their competitive fire flickers and dies. If artists start to value lifestyle and perks and fame more than their art, they lose their edge. Priorities become distorted. Decision-making goes off in crazy directions, and core passions-sport, art, neurosurgerysuffer.

Our core passion must always be serving our patients. Losing sight of this priority and letting anything come between us and the oath we took to serve our patients are the first steps on the road to disaster. We do not want to be one of those neurosurgeons who have become the lead story on news websites for all the wrong reasons. And our community of neurosurgeons does not want us there, either.

The stakes are especially high for neurosurgeons and our patients because of the very nature of what we do. As mentioned earlier, other specialties as well as society at large hold us in particularly high regard. But if we climb very high, we can also fall very low. How do we avoid such terrible mistakes? Simple: remember what our duty is, and remember that what we do is more than just a job. It's a calling. Most of all, it is a privilege to serve our patients and our communities.

Amid this somewhat idealistic discussion of priorities, it is important to acknowledge the realities of the world in which we live. The real world can get messy and dirty. Even Mother Teresa had to balance her checkbook. We cannot allow ourselves to become so overwhelmed with gratitude that we passively accept whatever comes our way from those who want to regulate what we do and how we do it.

Medicine has become a very crowded space. Available resources are far outmatched by needs. Our ability to care for our patients will suffer if we fail to engage, and sometimes argue with, those who may make it difficult for us to give proper care to our patients or to carry out the research and education that keep our specialty so dynamic. We will prevail because we have our patients' best interests at heart, and because we are blessed to have incredibly energetic and creative individuals within neurosurgery. Even though we are definitely in the arena, to evoke Teddy Roosevelt's famous phrase, there is no reason to make disagreements personal or to become mean-spirited. If we face a temporary setback, we will take the high road and set our sights on the longer time horizon.

Another strength of our specialty is that organized neurosurgery clearly defines its priorities and goals for legislation and policy. These goals are reevaluated every year and are always centered on what is best for our patients and our specialty. This consistent and transparent approach has earned us the respect even of those who disagree with us.

\section{Summary and Call to Action}

Many people sacrificed, accommodated, and picked up the slack so that I could spend so many hours working for this great organization-my wonderful family most of all. Underlying all these thanks to individuals is a profound sense of gratitude for being able to practice the profession I love in this country of incredible opportunity.

Service is the core of our profession and of our humanity. We as individuals and as a profession need to embrace the idea of a new triple threat, someone who excels as an 
administrator, advocate, and altruist. Dr. Gene Curtsinger's list of activities that take us outside of ourselves-art, religion, sex, and sports, plus selfless heroism and the performance of surgery-is made up of specific episodes. A mindset focused on service to others is a type of activity that flows continuously and is always humming in the background of a well-ordered life. Seen in this context, the costs of service are miniscule compared to its benefits.

The best argument for service is that it is the right thing to do. And doing the right thing for the right reasons makes us not only better doctors, but better people as well.

Many of these comments are unconventional and perhaps even uncomfortable reminders of the enduring virtues that are essential if we are to be good physicians and decent human beings. If you are uncomfortable, use that as an opportunity to look inward. As I have challenged myself, I am challenging you to reflect not only on what motivates you, but also on the deeper meaning and rewards of those motivations for others as well as yourselves.

What does all this mean for us? It is simple: pay it back. Our work has real meaning, and the privilege of doing that work makes us the luckiest people on this planet. I encourage you, and again I challenge you, to focus your many talents-your compassion, your intelligence, your work ethic, your incredible life experience-into making this world a better place.

The need is great. The opportunity is even greater, and it is available to every one of us.

Thank you for the privilege of serving you.

\section{Acknowledgments}

We thank those who provided valuable feedback and suggestions during the conceptualization and writing of this manuscript, especially Peter Buckley, Ron Hayes, Alice Kelsey, and Chris Shaffrey.

\section{References}

1. Acker L: Portland surgeon aids victims at scene of Amtrak derailment. OregonLive. December 18, 2017. (https://www. oregonlive.com/pacific-northwest-news/index.ssf/2017/12/ portland_neurosurgeon_triages.html) [Accessed August 3, 2018]

2. Braudy S: He's Woody Allen's not-so-silent partner. New York Times. August 21, 1977; Sec 2, 11 (https://www. nytimes.com/1977/08/21/archives/hes-woody-allensnotsosilent-partner.html) [Accessed August 3, 2018]

3. Centers for Medicare \& Medicaid Services: National Health Expenditure Data-Historical: Highlights. CMS.gov. (https:// www.cms.gov/Research-Statistics-Data-and-Systems/ Statistics-Trends-and-Reports/NationalHealthExpendData/ NationalHealthAccountsHistorical.html) [Accessed August 3, 2018]

4. Covey SR: The 7 Habits of Highly Effective People. New York: Simon \& Schuster, 1989

5. Csikszentmihalyi M: Flow: The Psychology of Optimal Experience. New York: Harper \& Row, 1990

6. Himmelstein DU, Woolhandler S: The current and projected taxpayer shares of US health costs. Am J Public Health 106:449-452, 2016

7. Kahneman D, Deaton A: High income improves evaluation of life but not emotional well-being. Proc Natl Acad Sci U S A 107:16489-16493, 2010

8. New American Bible, Revised Edition. Washington, DC: United States Conference of Catholic Bishops, 2011

9. World Bank: Poverty: Overview. World Bank. (http://www. worldbank.org/en/topic/poverty/overview) [Accessed August 3, 2018]

10. World Bank: World Development Report 1990: Poverty. New York: Oxford University Press, 1990 (https:// openknowledge.worldbank.org/handle/10986/5973) [Accessed August 3, 2018]

11. Zander RS, Zander B: The Art of Possibility: Transforming Professional and Personal Life. Boston: Harvard Business School Press, 2000

\section{Disclosures}

The authors report no conflict of interest concerning the materials or methods used in this study or the findings specified in this paper.

\section{Correspondence}

Alex B. Valadka: avaladka@gmail.com. 